\title{
LA AUTOBIOGRAFÍA Y SUS GÉNEROS AFINES
}

\author{
Maria Antonia Álvarez \\ UNED
}

La autobiografia es una forma literaria entre otras muchas - poesía, lírica, memorias, confesión o diario- en la que el escritor habla sobre sí mismo y los acontecimientos de su experiencia personal; es, por tanto, la narración de la vida de una persona, escrita por ella misma. El autobiógrafo conoce su pasado desde la perspectiva limitada de su propia imagen y, queriendo expresar la verdad de ese pasado, adopta estrategias verbales específicas para superar esta limitación.

Como características comunes a la mayoría de las autobiografias hay tres importantes: que se trata de una obra de madurez -o mejor dicho de vejez-, que pertenecen a personas conocidas en sus diferentes profesiones y que hay una revisión del transcurso de la vida junto con la exposición de los motivos que impulsan al autor a escribirla. Puede ser apología o testimonio, según sienta el propio escritor la necesidad de justificar ante el lector sus ideas y acciones o la obligación de dejar constancia de los hechos de los que fue testigo privilegiado, con la pretensión de ser útil a sus semejantes.

Aunque el instinto autobiográfico sea tan antiguo como el acto de escribir, según Wintraub (1978:821), sólo desde 1800 ha concedido importancia el hombre occidental a la autobiografia. La aparición del término tiene lugar en Alemania a principios del siglo XIX, y el Oxford English Dictionary atribuye el primer uso en inglés a Southey, en 1809, en un artículo de literatura portuguesa. El género consigue su total dimensión y riqueza cuando el hombre occidental adquiere un claro convencimiento histórico de su existencia, y si la autobiografía logra una función cultural significativa hacia 1800 , quiere decir que forma parte de la gran revolución intelectual marcada por la aparición del «historicismo».

La palabra griega bios, colocada en el centro de la palabra autobiografía - entre autos y graphe-, proporciona la raiz para una serie completa de 
expresiones inglesas. Si bios es el curso histórico de una vida, entonces en cualquier momento presente de esa vida es necesariamente cierto que todas las cosas han seguido su curso y que nada permanece: el término bios incorpora simultáneamente el sentido del curso de una vida visto como proceso más que como entidad estable, y la única configuración psíquica de que es esta vida y no otra.

Los primeros textos autobiográficos preceden con mucho a la palabra que los designa. Los críticos están generalmente de acuerdo en que las Confesiones de San Agustín ya eran una verdadera autobiografia, escrita catorce siglos antes de la invención de la palabra. Rousseau, que utilizó el mismo título para el más conocido de sus escritos autobiográficos, reconocía al menos otros dos antecesores: Jerôme Cardan, 1575 y Montaigne, hacia la misma fecha. Otras autobiografias importantes son las de Benvenuto $\mathrm{Ce}$ llini, c. 1560, Santa Teresa, poco después, y Bunyan, 1666 (May, 1982:121). La instauración de una verdadera tradición literaria de la autobiografia data de mediados del siglo xviII, y su impulso se debió principalmente a la obra de Rousseau. El éxito del libro, que comenzó a escribir en la década de 1760 , originó la toma de conciencia colectiva de la existencia literaria de la autobiografia en las principales culturas europeas e incluso en la norteamericana, ya que Benjamin Franklin comenzó a escribir en 1771 su Autobiography, terminándola en 1790. Es a partir de ese momento cuando aumenta el número de autobiografias y no solamente la publicación de las Confesiones de Rousseau afectan a la cantidad, sino también a la calidad de los escritos autobiográficos. Es, por tanto, el éxito de Rousseau el que consagra la autobiografía y la hace digna de ser admitida entre los géneros literarios con un carácter totalmente independiente de todos ellos.

Parece que la vocación autobiográfica puede responden a cualquier motivación y la diversidad de autores desafia toda clasificación. En vista de la diversidad de las obras autobiográficas que han ido apareciendo, casi podría llegarse a la conclusión de que parece no existir una auténtica forma autobiográfica aunque sí pueden hacerse varias generalizaciones y ver aspectos comunes que forman el núcleo de las funciones que debe realizar un texto autobiográfico. Traducido en reglas, podrian agruparse en tres fundamentales:

1. El autobiógrafo realiza el doble papel de ser la fuente del tema y el que estructura el texto, el autor siempre es el responsable de la creación y ordenación del texto, y aquí también se ejemplifica en ese texto, sobreentendiéndose que comparte la misma identidad.

2. Los acontecimientos que se narran en conexión con el autobiógrafo, se afirma que han dado lugar a la acción; bajo las convenciones existentes, se exige la categoría de "verdad» para lo que narra la 
autobiografía y se espera que el lector acepte los hechos como verdaderos, aunque es libre de poder comprobarlos o rechazarlos.

3. Se rechace o no la narración y vuelva o no a formularse en otra forma más aceptable o desde otro punto de vista, lo que es manifiesto es que el autobiógrafo cree en lo que narra.

Toda autobiografia ofrece la ilusión de que el pasado vuelve a la vida, pero a pesar de lo convincente que pueda resultar el texto autobiográfico, el pasado es una ilusión creada por la mente del artista, que ahora lo recrea.

El acto de escribir una autobiografia es una estrategia que el ser humano desarrolla para hacer que su vida trascienda. La creación autobiográfica, como arte literario, es la forma que toma nuestra vida en la cual el pasado ocupa el presente, gobierna el presente, pero en realidad todo poder genuino reside en el momento de la creatividad. El escritor se recuerda a sí mismo como adolescente, su memoria va dando forma a esos recuerdos y va creando la obra autobiográfica con la ayuda de la lengua, la expresión más perfecta del ser humano en cuanto a la cultura. La historia personal se va desplegando poco a poco en una vida, en el tiempo y fuera del tiempo. El contenido de una autobiografia no es suficiente para crear la verdad sino que lo que transforma el contenido en verdad es el contexto que aparece en el contenido.

Cualquier texto autobiográfico requiere un análisis en dos direcciones, según Lejeune (1971:66): la poética, descripción teórica del género y de las formas que utiliza, y la crítica, lectura inperpretativa del texto. Estas dos direcciones se presentan normalmente de forma complementaria, evitando así que una de ellas adquiera mayor importancia y controle a la otra.

Por lo que respecta a la primera, pueden hacerse varias tentativas de definición del género, para pasar después al problema más general de la forma de este género y de los métodos de estudio a aplicar.

En cuanto a la segunda, los principales problemas que presenta la lectura interpretativa de un texto autobiográfico son:

1. el lugar y la función de este texto dentro del conjunto de la obra del autor;

2. el orden de la narración autobiográfica, y

3. la relación del narrador con su narración y su héroe.

El estudio de estos tres factores está delimitado por dos demarcaciones que hay que tratar de hacer complementarias: el estudio poético y la interpretación analítica, ya que ambas coinciden en lo que debe ser siempre la 
primerà fase de cualquier estudio autobiográfico, que es principalmente de un fenómeno de la lengua.

Ya en L'autobiographie en France Philippe Lejeune esbozaba, y ahora completa (1975:14), una posible definición de la autobiografia, limitándola históricamente a un periodo de dos siglos - desde 1770 - y a la literatura europea. No quiere con ello decir que no admita la existencia de una literatura personal anterior a esa fecha, ni fuera de Europa, sino simplemente que la forma en que concebimos la autobiografia puede resultar anacrónica o poco pertinente fuera de estos límites. Textualmente parte Lejeune de la posición del lector, que es el destinatario del texto y quien tiene que hacerlo funcionar. Para él la autobiografia es la narración retrospectiva en prosa que hace una persona real de su propia existencia, poniendo énfasis en su vida individual y principalmente en la historia de su personalidad.

El que la crítica literaria no se hubiera ocupado antes del género autobiográfico se debe, según James Olney (1980:24), a diversas razones, como son el doble hecho paradójico de que a la autobiografia se la considera por unos inferior a la literatura y por otros superior a ella, a la insistencia de la crítica de que era esencial que una obra literaria presentara armonia, brillantez y sentido completo, requisitos que a veces no reunía, y ser un arte de autorreflexión o autocrítica quedando, en consecuencia, la crítica de la autobiografia dentro de la literatura en vez de al margen. A lo largo de su obra, el escritor puede discutir y analizar el acto autobiográfico mientras lo realiza: San Agustín, Montaigne, Rousseau, Henry James están siempre explicando lo que hacen, incluso cómo lo hacen, y esto es totalmente diferente de las necesidades de verosimilitud novelesca bajo las cuales actúa el escritor de ficción.

Otra tendencia de la crítica es considerar la autobiografía como un autorretrato; el yo piensa y actúa, sabe que existe en soledad y con otros. Un retrato es espacio y tiempo, ilusión y realidad, pintor y modelo; cada elemento hace una petición y una concesión. El autorretrato, por el contrario, no deja lugar a una posible separación: el artista-modelo, alternativamente, tiene que posar y pintar, componer y formar parte de la composición.

Karl J. Wintraub (1978:821-48) cree que debemos diferenciar el auténtico escrito autobiográfico de ese género parecido que es el autorretrato literario. Por un lado, si la autobiografia es la forma artística en la que un yo rememora su vida, esa forma está condicionada por la concepción predominante de la vida, y puesto que la vida es proceso, la autobiografia ha de contar con unos procedimientos internos que nos ayuden a verlo. Sin embargo, el autorretrato literario es simplemente un retrato estático del momento y en él no se descubre la naturaleza ni la verdadera estructura de la personalidad del autor. La auténtica autobiografia, por el contrario, equilibra los elementos diacrónicos, y si describe un hecho ocurrido en un momento dado, lo hace para ayudar a comprender el desarrollo a través del tiempo. 
Cuanto más predomina la convicción de que la vida es un conjunto de datos biográficos y no biográficos, más se impone la tendencia a hacer patente la vida en la historia en vez de encapsularla en quintaesencias filosóficas. Afirmar que el hombre no tiene naturaleza sino historia nos lleva a una posición historicista, pero supeditar el concepto del hombre como ser que puede definirse en términos de su naturaleza y de su esencia formal al no estar circunscrito de forma significativa por su historia, en todos y cada uno de los momentos en el tiempo, supone comprender la noción de la vida humana como proceso, en términos de un justo equilibrio entre la naturaleza y la historia del hombre, con consecuencias considerables para las diferentes formas de autobiografia.

No obstante, dentro de esta diversidad, en toda autobiografia hay que tener en cuenta tres elementos básicos: el carácter, la técnica y el tema (Howard, 1980:85).

El carácter está determinado por varios factores, como pueden ser su sentido del yo, del lugar, de la historia y de los motivos que impulsan a escribir. En la figura del autor hay que distinguir al que cuenta la historia $\mathrm{y}$ al que actúa como protagonista; aunque sean la misma persona el artista y el modelo, hay que apreciar sus puntos esenciales de separación, pues comparten el mismo nombre, pero no el mismo tiempo y espacio. El narrador siempre sabe más que el protagonista, aunque permanezca fiel a la ignorancia de éste en atención al suspense de la historia. Al acercarse el pasado al presente, las acciones del protagonista van armonizándose con el presente del narrador.

La técnica incluye esos mecanismos plásticos -estilo, imágenes y estructura- que configuran el autorretrato desde su interior hacia afuera. El estilo no está subordinado al contenido, pero es un dispositivo formal que tiene importancia propia. Incluso las elecciones estilísticas más simples de tiempo o persona tienen directamente significado, puesto que conducen a efectos más importantes, como la metáfora y el tono.

El tema, esas ideas y creencias que dan a la autobiografia su significado, o al menos la convierten en una réplica consistente del escritor, puede surgir de la filosofia general del autor, la fe religiosa o las actitudes culturales o politicas. El tema es personal, pero también es representativo de una época y, al igual que otras obras literarias, puede ilustrar la historia de las ideas. En realidad, la autobiografia tiene una base temática principalmente inclusiva, ya que sus escritores constantemente echan mano del amor, el recuerdo y la muerte, lo que atrae a un gran número de lectores. Hay que atribuir estos temas a causas históricas, observándose cambios en la interacción de autores y lectores a través de los siglos, pero este camino puede conducir a generalizaciones más amplias; una práctica más simple es observar cómo el autobiógrafo desarrolla su tema para dar un sentido de unidad intelectual 
a su yo, a su historia y a sus lectores. El tema de la autobiografia es la vida, puesto que la historia no es admisible que termine en la muerte, ya que la mano del escritor ha de actuar mientras tiene movimiento.

Estos tres elementos -el carácter, la técnica y el tema- operan como factores contiguos en la autobiografia, pero se examinan mejor en serie. Cada uno de ellos se refiere a un aspecto único de la composición: al escritor el carácter, a la otra la técnica y al lector el tema. No obstante, los tres forman una única cadena de relaciones, avanzando desde el motivo al método y al significado.

Aunque según algunos críticos la autobiografia aún no está totalmente separada de otras formas literarias que la precedieron en muchos siglos, sí podemos delimitar las fronteras que existen entre ellas. Lejeune (1975:14) estudia las condiciones que debe cumplir una obra para ser considerada autobiografia: la forma de lenguaje es una narración en prosa; el tema una vida individual, la historia de una personalidad; hay identidad entre el autor y el narrador; igualmente hay identidad entre el narrador y el personaje principal, y la perspectiva de la narración es retrospectiva.

Otros géneros afines, por el contrario, no reúnen todas estas condiciones, sino tan sólo algunas de ellas. Las memorias cuentan una vida individual, la historia de una personalidad; en la biografia se da la identidad del narrador y del personaje principal; la novela personal ofrece la identidad del autor y del narrador; el escrito autobiográfico tiene la prosa como forma de lenguaje; el diario íntimo está escrito con una perspectiva retrospectiva de la narración, y el autorretrato reúne las dos condiciones de tratarse de una narración en cuanto a forma de lenguaje y existir una perspectiva retrospectiva en cuanto a la posición del narrador.

Si comparamos la memoria, la confesión y la apología, hay que comenzar por definir la confesión como la historia personal que busca comunicar o expresar la naturaleza esencial, la verdad del yo; la apología como la historia personal que busca demostrar o realizar la integridad del yo, y la memoria como la historia personal que busca articular o recuperar la historicidad del yo. Si la confesión se ocupa del yo relativo a la naturaleza, a la realidad y la apologia del yo relativo al canon social, la memoria del yo relativo al tiempo, a la historia, al modelo y al cambio cultural. La confesión tiene la intención de comunicar nuestro yo, la apología de mostrar la integridad de nuestra vida y la memoria de recobrar el pasado (Hart, 196970:491). De todas estas definiciones se desprende que los tres géneros han de coincidir en muchos puntos y dificilmente puede aparecer uno independiente de los otros.

En cuanto a la relación de descendencia que pueda existir entre la autobiografia y su antecesora la biografia, por la similitud de la denominación, Georges May (1982:121) se pregunta que si la palabra autobiografía se de- 
riba de biografia, ¿no puede ocurrir lo mismo con las formas literarias que ambas designan? Pero es dudoso que la primera recibiera algo de la segunda en cuanto a forma, y sus antecedentes literarios habría que buscarlos entre la memoria y la novela principalmente. Pero no quiere esto decir que la autobiografia no deba algo a la biografia, ya que ambas tienen al menos en común un objetivo: hacer de una vida humana el tema de un libro.

Entre las diferencias fundamentales de la biografia y el género autobiográfico está el papel de la muerte. Las autobiografias no finalizan con la muerte del personaje: la esencia de cualquier autobiografia es que jamás puede llegar hasta el fin, que nunca puede decir la última palabra, como hace el biógrafo oficial. Si uno de los móviles fundamentales del escritor es triunfar sobre la muerte, nunca llega a conocer si podrá alcanzar este fin. Por el contrario, el biógrafo, desde el momento en que comienza a escribir, sabe que la memoria de su personaje ya se ha perpetuado más allá de la muerte. La ausencia de la muerte en la narración es una de las condiciones inherentes a la autobiografia.

Otra diferencia importante es el papel de la memoria. Los materiales de que se sirve el biógrafo son, al igual que los del historiador, exteriores a él y puede distanciarse de ellos para someterlos a una crítica objetiva. Por el contrario, la autobiografia trabaja con materiales subjetivos, los propios recuerdos. Puede basar su obra en documentos ajenos a él, como cartas, e interpretarlas antes de incluirlas en el texto.

El tercer elemento que diferencia el género autobiográfico del biográfico es el orden de presentación. El primero procede remontando el curso del tiempo, partiendo del presente de la narración para alcanzar el pasado de la experiencia, objeto de su obra; el segundo también escribe en el presente, pero cuando habla de la infancia de su personaje, lo conoce por la documentación, no por la experiencia.

El escritor percibe su vida como compuesta de estratos de recuerdos entre los cuales el más elevado, el que está en la superficie, es el último, el que limita con el presente. La vida que ha de construir el biógrafo basándose en la documentación que posee, consta de episodios dispuestos cronológicamente en sentido inverso, del nacimiento a la muerte; su personaje se construye envejeciendo en tanto que, para el autobiógrafo, la vejez - experiencia vivida-, lejos de ser un principio de construcción, conduce inevitablemente a la muerte.

En el Lerousse (1986:979) se dice que se adoptó el hábito de dar el nombre de autobiografia a esas memorias en las que aparecen más destacados los hombres que las escribieron que los acontecimientos en que se vieron mezclados. Sin embargo, en las memorias el lugar reservado a los acontecimientos, a la historia misma, es mayor que el que se refiere a la personalidad del autor. En efecto, la definición que da el Trésor es «la relación escrita de su propia vida, en lo que ésta tiene de más personal». Sinónimo: 
memorias, que ponen el acento sobre los acontecimientos exteriores (1974:978).

En ambos géneros siempre podemos encontrar la identidad del escritor y la experiencia que cuenta, pero el tema esencial de toda obra autobiográfica es concretamente la realidad experimentada y no la esfera propia del hecho externo. La realidad externa está incluida en la experiencia, pero la modificación de nuestra vida al formar la experiencia se ve desde el interior. La autobiografia presupone un intento de escribir por reflejar la esfera íntima de su experiencia, dando por sentado que se trata de un mundo interior de experiencia importante. En la memoria el hecho externo se traslada a la experiencia consciente, pero la mirada del escritor se preocupa menos por la experiencia interna que por la esfera externa del hecho. El interés de la memoria se centra en el mundo de los acontecimientos, de los sucesos, en la narración de los hechos significativos; idealmente aspira al ojo omnipresente de Dios. Por el contrario, la autobiografia se acerca más a las características básicas del género cuando el tema real de su contenido es el carácter, la personalidad, las propias ideas, todos estos conceptos dificiles de definir, que en último lugar determinan la coherencia interna y el significado de la vida. La auténtica autobiografía es:

... un fluir en el cual la propia consciencia se abre paso suavemente a través de la experiencia interrelacionada. Puede tener funciones tan diversas como la explicación, el descubrimiento, la clasificación, la formación, la presentación o la justificación del yo. Todas estas funciones se interpenetran fácilmente, pero todas están centradas en un yo consciente: consciente de su relación y de sus experiencias (Wintraub, 1978:824).

La línea divisoria entre la autobiografia y la memoria es muy dificil de fijar: la memoria se refiere más directamente a los acontecimientos públicos y la autobiografia a las relaciones privadas. La diferencia es principalmente de contenido y no afecta a la forma de la composición. No hay ninguna autobiografia que no sea de alguna manera una memoria y no hay memoria sin información autobiográfica; las dos están basadas en la experiencia personal, la relación cronológica y la reflexión, pero hay un objetivo diferente en la atención del autor. En la verdadera autobiografia, la atención se centra en el yo, y en la memoria en los otros. Es natural que las autobiografias de los políticos y de los hombres de estado sean casi siempre, en esencia, memorias.

La auténtica autobiografia implica la reconstrucción del movimiento de una vida, de una parte de la vida, en las circunstacias reales en que vivió. Su centro de interés es el yo, no el mundo exterior, aunque necesariamente el mundo exterior debe aparecer, de forma que en el intercambio producido 
con su entorno, la personalidad encuentre su forma peculiar. Pero la reconstrucción de una vida es una tarea imposible. La experiencia de un solo día es ilimitada en su radiación hacia el pasado y hacia el futuro. La autobiografia es una interacción, una colisión, entre el pasado y el presente; su significación es más la revelación de la situación actual que el descubrimiento del pasado, y supone un fracaso el no saber representar esta posición presente. La sutil penetración del pasado por el presente afecta no sólo a la forma de la autobiografía sino también a la manera en que está descrita, al estilo. No obstante, por lo que más frecuentemente fracasa un escritor es por no crear ese punto de encuentro significativo entre el individuo y el mundo exterior que ilumina a ambos, aunque tiene enfoques distintos hacia uno u otro según la intención del autor sea autobiográfica o se dirija hacia el otro género tan similar, la memoria.

Por otro lado, hay autobiografias llamadas memorias por sus autores. Según Georges May (1978:141-81), la palabra autobiografía tuvo comienzos dificiles en la lengua francesa, que prefería las de memorias o recuerdos. La diferencia sobre este punto con la lengua inglesa es muy grande ya que desde 1849 la famosa obra de Benjamin Franklin, conocida hasta entonces bajo el título de Vida o Memorias, se reimprimió en Nueva York con el de $\mathrm{Au}$ tobiography y actualmente sigue conociéndose con este título, y ya en el año 1909 Anna Roberson Burr publicó en Estados Unidos una obra llamada The Autobiography. Tampoco existe una frontera clara que separe los dos géneros. Surgida originariamente de las memorias, la autobiografia no ha adquirido de hecho más que una autonomía precaria.

Existe igualmente una gran similitud entre la autobiografia y el diario, principalmente en la reflexión sobre el pasado. El autor de un diario no puede tener la ilusión de escribir sobre el presente, a pesar de que en este caso el pasado sea inmediato comparándolo con la lejanía de la autobiografia. Puede establecerse también la analogía entre las etapas del día y las de la vida: el escritor que al llegar la noche anota en su diario los hechos salientes de la jornada conserva una analogía con el autobiógrafo que emprende la tarea de recuperar el pasado al finalizar su vida; la diferencia es sólo cuantitativa. Otra afinidad entre estos géneros es que ambos escritores avanzan en la misma dirección temporal: no del pasado al presente, sino en sentido contrario al transcurso de la vida; del presente al pasado, del momento en que escribe al momento en que vivió. Las diferencias, no obstante, son numerosas. Mientras que el diario se escribe día a día y sólo abarca en cada anotación lo que interesó en un breve espacio de tiempo, en la autobiografia se abarca el conjunto de una vida escrita después de haber transcurrido la mayor parte de ella. No quiere esto decir que el diario haya de escribirse forzosamente todos los días; a veces es interrumpido y retomado después de un intervalo más o menos largo. Tampoco la autobiografia ha de referirse necesariamente a todo el período de tiempo transcurrido hasta que el escritor se decide a narrar su vida; es muy corriente que el autobió- 
grafo - voluntariamente o no- abarque solamente un período de su vida relativamente limitado. Al ser mayor en el caso de la autobiografia que en el del diario la distancia entre el tiempo de la experiencia y el de su anotación, el recuerdo anotado no tiene la misma frescura, pero tampoco la confusión de la primera impresión; ha tenido tiempo para reposar en la memoria y para modificarse al contacto con otros recuerdos que fueron registrados antes o después. Por otro lado, el recuerdo que se anota demuestra su importancia al ser distinguido jerárquicamente de los que cayeron en el olvido.

Si la ventaja del diario es la precisión y la exactitud, la de la autobiografia es la de la reflexión a que da lugar el paso del tiempo; la distancia entre el tiempo de la narración y el tiempo del acontecimiento es lo que permite al escritor dar más tarde unidad a su aventura, proporcionarle una estructura, un edificio ordenado y armonioso. De ahí la importancia de la autobiografía en el mundo occidental: todas estas cualidades son las que caracterizan a nuestra cultura.

Lo que diferencia a la verdadera autobiografia del diario es el proceso de dirigir la narración por el significado presente de la vida. Las anotaciones diarias están caracterizadas por el hecho real de que un día tiene su fin y así incluso el escritor más preparado tiene que atribuir significación a segmentos o partes de la vida. Es cierto que un diario de muchos años revelará el desarrollo de la personalidad del escritor, pero lo hará de una manera totalmente diferente a la autobiografia. El diario, la carta, la crónica, los anales son exclusivamente interpretaciones momentáneas de la vida; su valor está en la anotación fiel, no en extraer significados. Son una ayuda para acercar el pasado al presente cuando se analizan con mirada retrospectiva, mientras que la historia y la autobiografía sintetizan el pasado en el momento presente. La autobiografia y el diario tienen propósitos diferentes y se apoyan en distintos elementos formales. El incluir las anotaciones de un diario en obras autobiográficas produce un efecto poco acertado; una de las mezclas menos afortunadas podemos hallarla en la Autobiography de Gibbon, cuando brevemente utiliza las entradas de su diario para sugerir que «hubo una ocasión en que buscó un tema histórico apropiado para su estilo, donde el tópico del declinar de la vida no figuraba en absoluto» (Wintraub, 1978:827).

La diferencia formal entre diario y autobiografia consiste en que la segunda supone un análisis de la vida desde un momento determinado en el tiempo, mientras que el primero - a pesar de lo reflexivo que puede serse mueve a través de una serie de momentos en el tiempo. El escritor del diario anota lo que en ese instante le parece importante, pero no puede valorar la significación última. Incluso podría afirmarse que los mejores diarios son los que interesan menos de significados de largo alcance. $Y$ no hay una diferencia menor entre el tono expresivo del diario y el de la autobiografia, de tal manera que si se citan extractos de diarios en las auto- 
biografias, involuntariamente o no, dan clara evidencia de un cambio del centro de atención. El problema más complicado del autobiógrafo es que no relata hechos, sino experiencias; es decir, la interacción del hombre y los hechos o acontecimientos (Pascal, 1960:3-16). A lo que llama experiencia es simplemente a algo que tiene significado, y puede haber muchas variedades y matices de significados, tanto la respuesta directamente emotiva como el efecto inmediato en términos de comportamiento o pensamiento, pero hay también una significación futura que puede salir a la superficie solamente después de mucho tiempo, y la que adquiere la experiencia retrospectiva. A todas estas clases de significados hay que añadir un último tipo, que es decisivo: el significado que adquiere un acontecimiento cuando se contempla con la perspectiva de toda una vida.

En cuanto a la apologia, Georges May la define como «una intención autobiográfica movida por la necesidad de escribir con el fin de justificar en público las acciones que se ejecutaron o las ideas que se profesaron" (1982:47). Esta necesidad del escritor de justificarse, de restablecer la verdad, de corregir, rectificar o desmentir las calumnias de que haya podido ser objeto, a veces se encuentra mezclada con la intención de glorificarse o la de venganza. Rousseau denomina su obra autobiográfica Confessions, mientras que su intención es apologética. La confesión es el motivo principal de la historia de Rousseau, que da integridad a toda su vida social. La obra es un acto característico de amistad hacia el confesor, una apología del confesor, para tratar de conseguir el fin social que no consiguió en vida.

Por tanto, ni la memoria, ni la confesión, ni la apología pertenecen por derecho propio al género autobiográfico; son tan sólo una intención autobiográfica. Los autobiógrafos comparten ciertas intenciones, en diversos grados y en numerosos modelos distintivos de interacción. No obstante, más que deducir expectativas fijas de las diversas clases de intención, deberíamos investigar cómo, por qué y con qué efecto esas intenciones diversas evolucionan y actúan en las diferentes autobiografias. De igual manera, deberíamos observan e interpretar las distinciones dinámicas de la forma y las evoluciones y conflictos del enfoque personal, según el escritor luche con las opciones de verdad e integridad al tratar de recuperar su historia personal.

\section{REFERENCIAS BIBLIOGRÁFICAS}

Gran Diccionario Universal du XIX Siècle (1966) Tomo I.

HaRT, Francis R., (1969-70) «Notes for an Anatomy of Modern Autobiography», New Literary History, Vol. 1. University of Virginia.

Howard, William L., (1980) «Some Principles of Autobiography», Ed. J. Olney, Autobiography: Essays Theoretical and Critical. Princeton, New Jersey: Princeton University Press. 
Lejeune, Philippe, (1971) L'autobiographie en France, ed. A. Colin, Paris: coll. «U2».

Lejeune, Philippe, (1975) Le pacte autobiographique. París: ed. du Seuil.

MAY, Georges (1982) La autobiografia (traducción de DANubio Torres Fierro). México: Breviarios del fondo del cultura económica.

OLNEY, JAMES (1980) «Dome Versions of Memory, some Versions of Bios: the Ontology of Autobiography", Autobiography: Essays Theoretical and Critical. Princeton, New Jersey: Princeton University Press, 1980.

Pascal, Roy (1960), Design and Truth in Autobiography. London: Routledge \& Kegan Paul. Weintraub, KarL L. (1978) «Autobiography and Historical Consciousness», Critical Inguiry. The University of Chicago Press. 